Isolation and identification of microorganisms with capacity to produce indole-acetic acid in onion crops of the state of Zacatecas

\title{
Aislamiento e identificación de microorganismos con capacidad de producción de ácido indol-acético en cultivos de cebolla del estado de Zacatecas
}

Hádrian González-Torres ${ }^{1}$, Arturo Alejandro Rodríguez-Moreno ${ }^{1}$, María Laura Eugenia RomeroJaramillo$^{1}$, Veronica Segovia-Tagle ${ }^{1 *}$, Francisco Alejandro Paredes-Sánchez ${ }^{1}$, Karol Karla García-Aguirre $^{1}$, Elsa Verónica Herrera Mayorga ${ }^{1}$, Leticia Bravo-Luna ${ }^{2}$.

${ }^{1}$ Laboratorio de Biología, Unidad Profesional Interdisciplinaria de Ingeniería campus ZacatecasInstituto Politécnico Nacional, Zacatecas, México. ${ }^{2}$ Departamento Interacciones Planta-Insecto, Centro de Productos Bióticos-Instituto Politécnico Nacional.

*Corresponding author.

E-mail address: vesetave@hotmail.com (V. Segovia-Tagle).

Article history:

Received: 8 December 2016 / Received in revised form: 24 May 2017 / Accepted: 17 June 2017 / Published online: 1 July 2017

\section{https://doi.org/10.29267/mxjb.2017.2.2.151}

\begin{abstract}
Growth promoting bacteria have the ability to function as biofertilizers that provide the plant nutrients, as well as the production of phytohormones such as indole-acetic acid (IAA). The evaluated strains were isolated from onion crops soil of the city of Fresnillo, Zacatecas, Mexico. Six strains positive for the production of indole-acetic acid were obtained. All six strains were identified by DNA extraction and subsequent bidirectional sequencing of the $16 \mathrm{~S}$ gene. The strain identified as Pseudomonas cedrina was the largest producer of indole-acetic acid with a value of $174 \pm 0.06 \mu \mathrm{g} / \mathrm{mL}$; the bacteria identifided have potential to be used in the formulation of biofertilizers.
\end{abstract}

Keywords: Indole-acetic acid, phytohormones, 16s gene.

\section{RESUMEN}

Las bacterias promotoras de crecimiento tienen la capacidad de fungir como biofertilizantes que proveen a la planta nutrientes, así como con la producción de fitohormonas como el ácido indolacético (IAA, por sus siglas en inglés). Se evaluaron muestras aisladas de suelo rizosférico de cultivos de cebolla de la ciudad de Fresnillo, Zacatecas, México. Se obtuvieron 6 cepas positivas 
para la producción de ácido indol-acético. Las seis cepas se identificaron mediante la extracción de ADN y la posterior secuenciación bidireccional del gen $16 \mathrm{~S}$. La cepa identificada como Pseudomona cedrina fue la mayor productora de ácido indol-acético con un valor de $174 \pm 0.06 \mu \mathrm{g} / \mathrm{mL}$; las bacterias identificadas presentan potencial para ser usadas en la formulación de biofertilizantes.

Palabras clave: Ácido indol-acético, fitohormona, gen 16s.

\section{INTRODUCCIÓN}

México es el doceavo productor de cebolla ocupando el $1 \%$ tanto de la superficie mundial como del volumen global. En 2013, la superficie sembrada de cebolla (Allius cepa) en México alcanzó las 44 mil hectáreas con un volumen estimado de 1.3 millones de toneladas. De la producción nacional, el $90 \%$ corresponde a cebolla blanca, $7 \%$ es morada, $2 \%$ amarilla y $1 \%$ cebollines. Zacatecas obtuvo una participación nacional de $13.1 \%$ en el 2012 con un estimado de 162.2 mil toneladas (SIAP-SAGARPA 2014). En el ámbito de la agricultura existe el desafío de aumentar el rendimiento y calidad en la producción en frutas y vegetales con el propósito de satisfacer las necesidades del consumidor evitando efectos adversos en el medio ambiente (Mader 2002). El suelo contiene diferentes grupos de microorganismos como bacterias, hongos, actinomicetos y algas que afectan la calidad y la salud de las tierras. La rizósfera es la región de intensa actividad microbiana, impulsado por la exudación de la raíz. La utilización de biofertilizantes se ha convertido en una práctica factible y se ha extendido su uso. Muchos biofertilizantes comerciales están basados principalmente en bacterias promotoras de crecimiento (PGPR, por sus siglas en inglés), que son microorganismos que benefician el desarrollo de la planta usualmente relacionado al incremento de nutrientes y a la disponibilidad de nitrógeno a la planta. Los beneficios que ofrecen consisten en incrementar los nutrientes en la zona de la raíz de la planta, la supresión de la muerte de las plantas (Zehnder et al., 2001), a través de la producción de metabolitos como sideróforos que secuestran la producción de hierro, péptidos que actúan como bioestimulantes, síntesis de antibióticos, producción de fitohormonas (como el ácido indolacético), enzimas y otras actividades asociadas, así como una mayor solubilización de fosfatos, competencia y colonización de la raíz y el suelo (Glick 1998). Todos estos factores contribuyen al incremento de la velocidad de germinación (Ahmad 2008). Las simbiosis plantamicroorganismo son influenciadas por cambios ambientales en la tierra, como el estrés hídrico, salinidad, deficiencias de nutrientes, alcalinidad y acidez (Hungría 2000). La aplicación de PGPR en los cultivos es atractivo ya que reduce el uso de fertilizantes químicos y pesticidas que usualmente contaminan el medio ambiente y reducen la sustentabilidad. Esto tiene un alto impacto tanto en el suelo como en los seres vivos, ya que se evita la posible contaminación de agua, tierra y efectos en las cadenas tróficas. Entre las cepas reportadas como PGRP se encuentran los géneros de Azotobacter, Azospirillum, Pseudomonas, y Bacillus, estas pueden afectar la germinación de la semilla. Las bacterias son requeridas para la biosíntesis de la celulosa en la cubierta de la semilla. El objetivo de este estudio fue el aislamiento e identificación de cepas nativas del estado de Zacatecas que presenten producción de ácido indolacético con la intención de ser usadas en la producción biotecnológica de biofertilizantes. 


\section{MATERIALES Y MÉTODOS}

\subsection{Muestreo de suelo y aislamiento de bacterias}

Se realizó un muestreo al azar en un campo de cultivo de cebolla del municipio de Fresnillo, Zacatecas, México. Se tomaron 3 muestras de suelo rizosférico en cultivo de cebolla blanca (identificadas como $\mathrm{C} 1$ y C2) y 1 de cebolla morada (identificada como C3) a un diámetro de 5 $\mathrm{cm}$ de la raíz de la planta. Las muestras se transportaron en bolsas de polietileno al vacío protegidas del calor y de la luz solar hasta su llegada al laboratorio de Biología de la UPIIZ-IPN. Para el aislamiento se pesaron $10 \mathrm{~g}$ de muestra en condiciones asépticas diluyéndolos en $90 \mathrm{~mL}$ de solución salina $0.85 \%\left(10^{-1}\right)$. A partir de la primera dilución se realizaron diluciones hasta $10^{-4}$. Las diluciones se sembraron por duplicado en agar nutritivo (MCD LAB®) y se incubaron por $24 \mathrm{~h}$ a $35^{\circ} \mathrm{C}$. Se realizó la tinción de Gram para descartar las colonias que presentaban forma de coco ya que no se tienen reportadas como PGPR. Se seleccionaron las colonias que presentaron una morfología microscópica bacilar para su aislamiento. Una vez obtenido el cultivo puro se sembraron por estría simple en tubos con agar nutritivo y se incubaron a $35^{\circ} \mathrm{C}$ por 24 horas. Al término del periodo de incubación los tubos se refrigeraron a $4^{\circ} \mathrm{C}$ para su conservación.

\subsection{Cinética de crecimiento bacteriano}

Se realizó una curva de crecimiento para determinar los tiempos viables para realizar la medición de producción de IAA. Se prepararon matraces con $250 \mathrm{~mL}$ de caldo nutritivo enriquecido con 5 g de glucosa y se etiquetaron con el código de la cepa correspondiente; se inocularon con una suspensión de células igual al tubo número 3 de Nefelómetro de McFarland. Se colocaron en una agitadora a $120 \mathrm{rpm}, 37^{\circ} \mathrm{C}$ por un periodo de 30 horas, midiendo la absorbancia cada hora en un espectrofotómetro PerkinElmer Lambda XLS a una longitud de onda de 540nm.

\subsection{Determinación de producción de ácido indol-acético (IAA)}

La producción de ácido indol-acético (IAA) se midió utilizando la técnica colorimétrica de Ehmann (Ehmann 1977). Las bacterias aisladas fueron inoculadas en medio caldo soya tripticaseína (MCD LAB®) adicionado con $0.01 \mathrm{mg}$ de L-triptófano (Sigma- Aldrich) y fueron incubadas a $30^{\circ} \mathrm{C}$ por 24 horas. Para la medición se tomaron $1.5 \mathrm{~mL}$ de los matraces y se vaciaron en tubos Eppendorf los cuales se centrifugaron a $6600 \mathrm{rpm}$ por 5 minutos, se tomó 1 $\mathrm{mL}$ del sobrenadante y se colocaron en tubos de ensayo donde posteriormente se adicionaron 2 $\mathrm{mL}$ de reactivo de Salkowsky $\left(0.01 \mathrm{FeCl}_{2}\right.$ en $\left.\mathrm{HClO}_{4}\right)$, se dejó actuar durante 20 minutos y finalmente se leyó la absorbancia a $530 \mathrm{~nm}$.

\subsection{Extracción de ADN}

Se realizó mediante el Kit de extracción y purificación de ácidos nucleícos Wizard Genomic A1120, de PROMEGA, siguiendo las instrucciones del proveedor, omitiendo la RNAsa. Se añadieron $1.2 \mathrm{~mL}$ del cultivo bacteriano con $24 \mathrm{~h}$ de incubación a un tubo Eppendorf de $1.5 \mathrm{~mL}$. Se centrifugó la muestra a 14,000 rpm durante 2 minutos, se removió el sobrenadante resultante. Para las bacterias Gram positivas se resuspendieron en $500 \mu \mathrm{L}$ de EDTA $50 \mathrm{mM}$ adicionado con 
$150 \mu \mathrm{L}$ de lisozima. Se incubaron a $37^{\circ} \mathrm{C}$ por 60 minutos y se centrifugaron a $14,000 \mathrm{rpm}$ removiendo el sobrenadante resultante; para las Gram negativas se omitieron estos pasos y se continuó con la metodología a partir de los siguientes pasos. A la pastilla se le añadieron $600 \mu \mathrm{L}$ de buffer de lisis nuclear mezclando por inversión. Se incubó durante 5 minutos a $80^{\circ} \mathrm{C}$ para después enfriarlo en hielo. Se agregaron $200 \mu \mathrm{L}$ de solución de precipitación de proteínas y se mezcló con ayuda del vortex. La muestra se incubó en hielo por 5 minutos y se centrifugó a 14,000 rpm durante 3 minutos. El sobrenadante se transfirió a un tubo Eppendorf limpio con 600 $\mu \mathrm{L}$ de isopropanol a $4{ }^{\circ} \mathrm{C}$ mezclándose por inversión hasta que se precipitó el ADN. La muestra se centrifugó a 14,000 rpm y se decantó. A la pastilla se le agregaron $500 \mu \mathrm{L}$ de etanol al $70 \%$ a $4^{\circ} \mathrm{C}$ por inversión. Se centrifugó a 14,000 rpm durante 2 minutos y se decantó el etanol dejando secar a temperatura ambiente entre 30-45 minutos, posterior a esto se rehidrató con $50 \mu \mathrm{L}$ de solución de rehidratación por $1 \mathrm{~h} \mathrm{a} 65^{\circ} \mathrm{C}$ y finalmente por $24 \mathrm{~h}$ a $4^{\circ} \mathrm{C}$.

\subsection{Electroforésis}

Se mezclaron $2 \mu \mathrm{L}$ de colorante Diamond 1 x y $5 \mu \mathrm{L}$ del ADN aislado, colocando esta mezcla en el pocillo del gel de agarosa $1 \%$. Se corrió la electroforesis durante 20 minutos a $80 \mathrm{~V}$. La visualización de la electroforesis se realizó en el fotodocumentador Cell Biosciences Alphalmager HP para observar los resultados de la extracción de ADN.

\subsection{Amplificación del gen 16s ribosomal}

Se tomaron los oligonucleótidos universales reportados por Campos y colaboradores en 2012. Con un tamaño de amplicón de 1400 pb, el ID del oligonucleótido fue Bac1 FW 5'AGAGTTTGATCAG-3' y 5'-GCGGTGTGTACAAGGCCCG-3'.

\subsubsection{Reacción en cadena de la polimerasa (PCR)}

Las bacterias seleccionadas se colocaron en un Termociclador Labnet Multigene Mini. El volumen final fue de $30 \mu \mathrm{L}$, la reacción de PCR contenía $50 \mathrm{ng} / \mathrm{mL}$ de ADN y las condiciones de la reacción fueron primers Bac1 FW y 16 s-1400 (0.1mM) dNTPs $(0.2 \mathrm{mM})$, buffer 1x y GoTaq DNA Polimerasa Bioline (0.125 U). Los ciclos del termociclador fueron desarrollados bajo las siguientes condiciones: $94^{\circ} \mathrm{C}$ por 3 minutos $(1$ ciclo $), 94^{\circ} \mathrm{C}$ por $30 \mathrm{seg}, 57^{\circ} \mathrm{C}$ por $30 \mathrm{seg}, 72^{\circ} \mathrm{C}$ por $30 \mathrm{seg}(30$ ciclos $)$ y finalmente $72^{\circ} \mathrm{C}$ por $3 \mathrm{~min}$ ( 1 ciclo).

Para evaluar el producto de la amplificación, se mezcló con $3 \mu \mathrm{L}$ del colorante Diamond 1x y $3 \mu \mathrm{L}$ del producto de PCR colocando esta mezcla en el pocillo del gel de agarosa $1.5 \%$ agregando marcador Ladder Plus 100 pb en el primer pocillo. Se corrió la electroforesis durante $1 \mathrm{~h}$ y $15 \mathrm{~min}$ a $80 \mathrm{~V}$. La visualización de la misma se realizó en el fotodocumentador Cell Biosciences Alphamager HP.

\subsection{Secuenciación}

Los fragmentos de ADN obtenidos se purificaron utilizando el protocolo de ExoSap-IT, la reacción se colocó en el termociclador bajo las siguientes condiciones: $37^{\circ} \mathrm{C}$ por 30 min y $80^{\circ} \mathrm{C}$ por 15 min. Los productos purificados de PCR se secuenciaron por medio de la tecnología 
Sanger en un secuenciador automático por capilaridad ABI PRISM 3100 en el laboratorio LANGEBIO-CINVESTAV.

\subsection{Identificación molecular}

Con las secuencias nucleotídicas se realizó la construcción de las secuencias consenso y la corrección de los cromatogramas utilizando el programa SeqMan V7.0.0 de la Suite Lasergene DNASTAR. Posteriormente las secuencias obtenidas fueron comparadas con la base de datos $\mathrm{nr} / \mathrm{nt}$ del NCBI utilizando el programa BLASTn para la identificación de las bacterias aisladas.

\section{RESULTADOS}

\subsection{Curva estándar de IAA}

En total se aislaron 39 cepas de microorganismos, de las cuales 17 corresponden a bacterias y 22 a hongos los cuales se mantuvieron en congelamiento para posteriores análisis.

Se realizó una curva estándar para determinar la concentración de IAA producido $(\mu \mathrm{g} / \mathrm{mL})$.

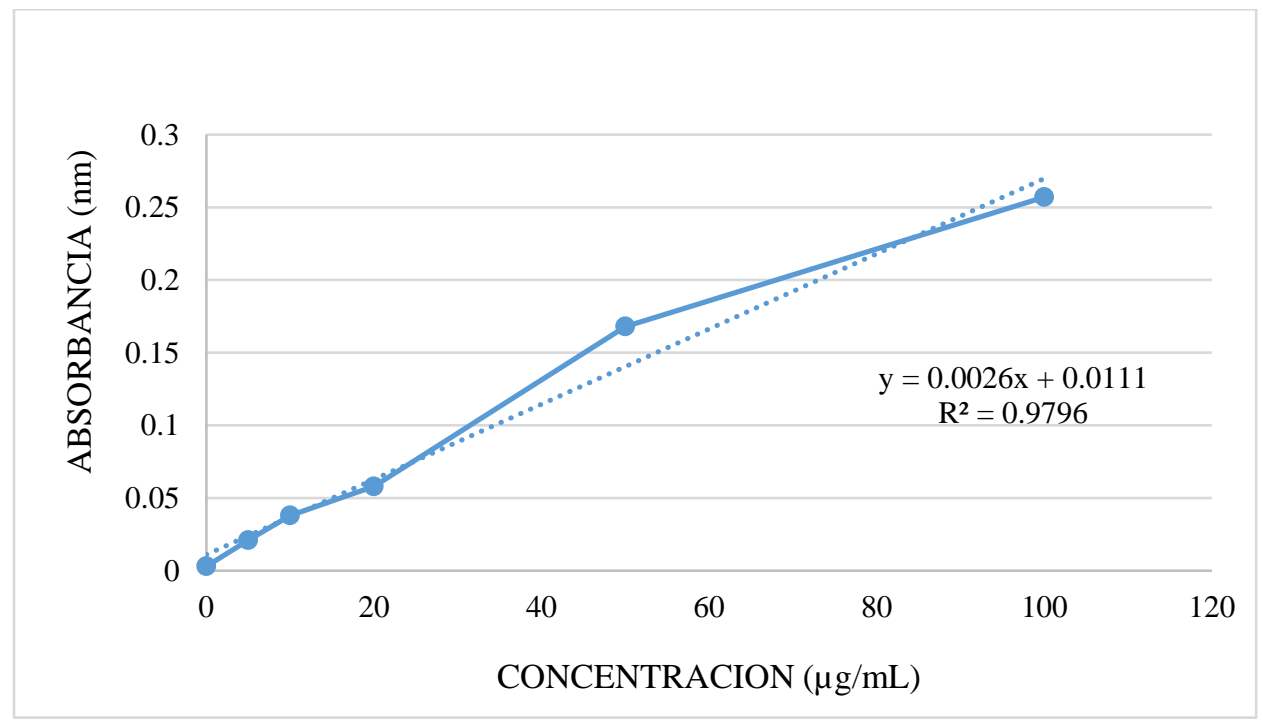

Fig. 1. Curva estándar de IAA.

\subsection{Producción de IAA}

Las cepas bacterianas que se consideraron positivas en la producción de IAA después de 24 horas de incubación se muestran en la tabla 1. 
Tabla 1. Resultados de producción de IAA positivos.

\begin{tabular}{cc}
\hline Muestra & $\begin{array}{c}\text { Concentración } \\
(\boldsymbol{\mu g} / \mathbf{m L})\end{array}$ \\
\hline C3B3 & 13.42 \\
C3B1 & $46.30 \pm 0.01$ \\
C1B3 & $174 \pm 0.06$ \\
C1B1 & 73.42 \\
C2B4 & $49.76 \pm 0.01$ \\
C2B2 & $88.23 \pm 0.02$ \\
\hline
\end{tabular}

\subsection{Reacción en cadena de la polimerasa (PCR)}

Para cada una de las bacterias aisladas a partir de la muestra de suelo que mostraron producción de IAA, fueron amplificadas mediante PCR punto final del gen 16s ribosomal. El tamaño teórico del amplicón es de 1400 pb.

En la figura 2 se muestran la amplificación de bacterias 1:C2B4; 2:C2B2; 3:C3B3; 4:C1B1; 5:C1B3; 6:T2B1; 7:C3B1.

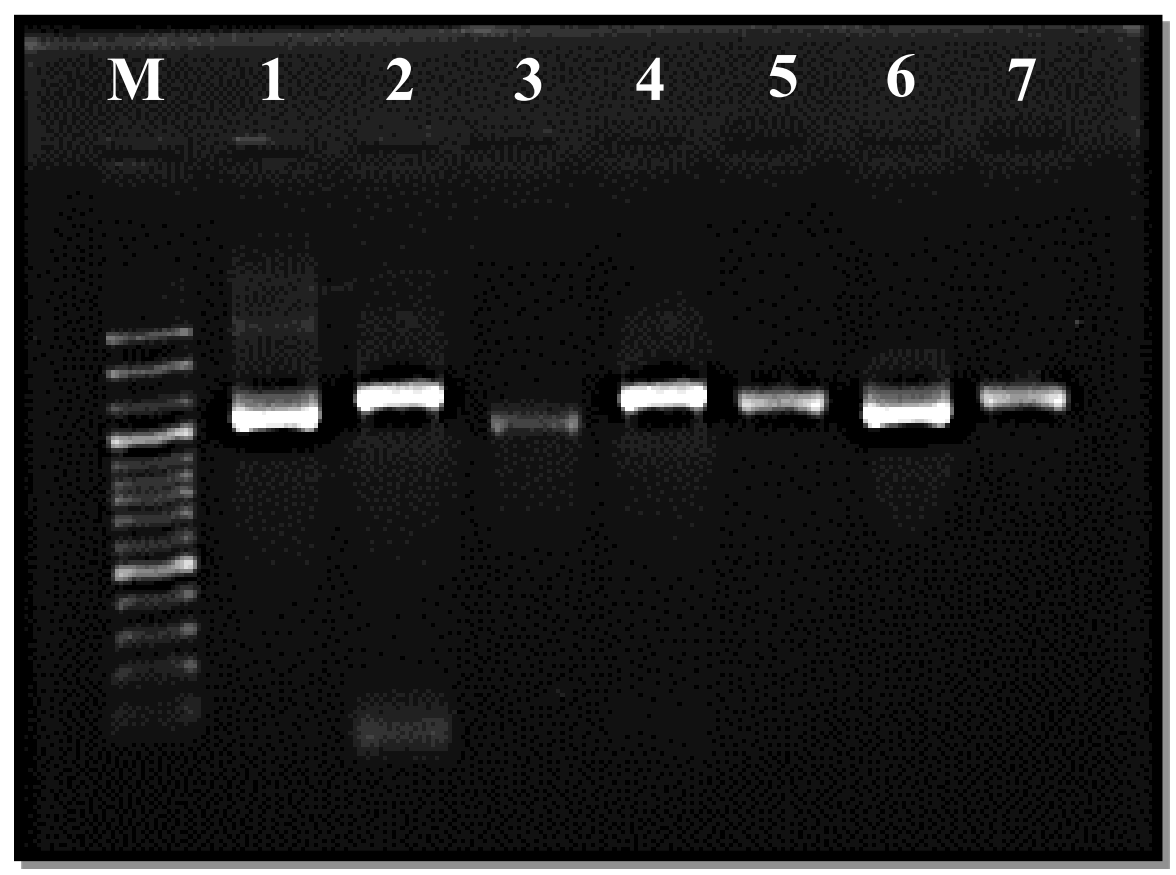

Fig. 2. Amplificación del gen 16s a 1200 pb Marcador Ldadder Plus 100 pb. 


\subsection{Construcción de los Contigs}

El amplicón obtenido fue secuenciado bidireccionalmente con la tecnología Sanger con los mismos oligonucleótidos de la amplificación. A partir de los resultados de este último proceso se obtuvieron las secuencias consenso para cada una de las muestras.

\subsection{Identificación molecular}

Las secuencias consenso fueron comparadas con la base de datos nr/nt del NCBI, utilizando la herramienta BLASTn.

Tabla 2. Resultados de la Identificación Molecular.

\begin{tabular}{ccccl}
\hline Cepa & $\begin{array}{c}\text { Contig } \\
(\mathbf{p b})\end{array}$ & E-Value & $\begin{array}{c}\text { \% } \\
\text { Similitud }\end{array}$ & Bacteria identificada \\
\hline C2B4 & 1348 & 0.0 & $\begin{array}{c}99 \% \\
1305 / 1307\end{array}$ & Bacillus megaterium \\
C3B3 & 1356 & 0.0 & $\begin{array}{c}99 \% \\
1303 / 1311\end{array}$ & Paenibacillus lautus \\
$94 \%$ & Bacillus aryabhattai \\
C2B2 & 1345 & 0.0 & $\begin{array}{c}1212 / 1288 \\
100 \%\end{array}$ & Pseudomona cedrina \\
C1B3 & 1329 & 0.0 & $\begin{array}{c}1309 / 1309 \\
99 \%\end{array}$ & Bacillus licheniformis \\
C1B1 & 1347 & 0.0 & $\begin{array}{c}1314 / 1319 \\
99 \%\end{array}$ & Aeromona salmonisida \\
\hline C3B1 & 1342 & 0.0 & $1306 / 1321$ & \\
\hline
\end{tabular}

La tabla 2 muestra la identificación molecular de las cepas, seguido por los valores de e-value que representa la probabilidad de que el alineamiento realizado sea debido al azar, por lo que un valor de cero o cercano a este indica que entre la secuencia obtenida y la base de datos del NCBI la homología es verdadera.

\section{DISCUSIONES}

Las cepas bacterianas fueron sometidas a cinéticas de crecimiento para evaluar a que tiempo alcanzaban la fase estacionaria, donde el triptófano es metabolizado por la bacteria y genera el ácido indol-acético; dicha fase se presentó a las 24 horas de incubación. El IAA pertenece al grupo de fitohormonas que generalmente se consideran dentro de las auxinas más importantes. La auxina es una hormona reguladora de muchos aspectos en el crecimiento de la planta y su desarrollo, incluyendo división celular y elongación, diferenciación, tropismo, dominancia apical, senescencia, abscisión y florecimiento (Woodward \& Bartel 2005).

Seis bacterias resultaron positivas en producción de IAA siendo estas las representadas en la tabla 1. La mayoría de los estudios recientes muestran que los organismos que producen IAA son en su mayoría Gram negativos (Lindow 1998). Se conocen pocas cepas Gram positivas que 
produzcan IAA, una de ellas es el género Bacillus (Wahyudi et al., 2011). Cuatro de las cepas aisladas resultaron ser Gram positivas.

Se ha reportado que la producción de IAA en las bacterias puede variar dependiendo de la especie y la cepa, y también está influenciada por la condición del medio de cultivo, la etapa de crecimiento y la disponibilidad del sustrato (Mutluru \& Konada 2007).

El uso de la técnica de Van Urk Salkowski para la detección de IAA es una importante opción para determinaciones cualitativas y semi-cualitativas que aseguren la presencia de la hormona en el sobrenadante de los medios bacterianos. La cantidad de ácido indol-acético producido por la bacteria fue detectado por el reactivo de Salkowski (Ehmann 1997). El agente reacciona con IAA y no interactúa con otros isómeros que no sea el L-triptófano y N-acetil-L-triptófano (Vaghasiat et al., 2011). Entre los positivos a la prueba las cepas C1B3 y C2B2 mostraron la mayor producción de IAA, $174 \pm 0.06$ y $88.23 \pm 0.02 \mu \mathrm{g} / \mathrm{mL}$ respectivamente. Por otro lado los aislamientos C3B1, C1B1 y C2B4 mostraron una producción menor de IAA, en un intervalo de 13.42-73.42 $\mu \mathrm{g} / \mathrm{mL}$, esto probablemente debido a la utilización de precursores de IAA en la síntesis de proteínas y la formación de otros compuestos de indol distintos del IAA (Dullaart 1970).

La producción de esta auxina se incrementa cuando el medio es suplementado con un precursor del IAA; el triptófano está confirmado como precursor por (Mutluru \& Konada 2007). La propiedad de sintetizar IAA es considerada como una herramienta efectiva para evidenciar microorganismos benéficos en términos de producción de IAA y que tienen efectos en el crecimiento de las plantas (Wahyudi et al., 2011). La inoculación con bacterias productoras de IAA inducen la proliferación de la raíz así como también muestran mejoras en la velocidad de germinación y velocidad de crecimiento de la planta, entre otras características de los PGPR (Zarrin et al., 2009).

Uno de los genes más ampliamente utilizados en la identificación molecular de microorganismos es el 16s ribosomal, ya que es un gen muy corto, con solo 1,542 pares de bases, y que puede ser rápidamente secuenciado. Los oligonucleótidos empleados en este estudio fueron diseñados, alineando la secuencia nucleotídica del gen 16s ribosomal de organismos de distintos géneros, en particular de Escherichia coli; por lo que se consideran universales ya que se diseñaron en regiones conservadas en secuencia nucleotídica del gen $16 \mathrm{~s}$.

Es importante recalcar que BLASTn puede realizar un alineamiento local por lo que puede arrojar valores erróneos de similitud por lo que para todos los casos se tomó en cuenta que la longitud de la secuencia alineada fuera cercana a los 1400 pb. A partir de la secuenciación bidireccional se obtuvieron secuencias de longitudes de 1329 nucleótidos en la cepa C1B3, alineando 1309/1309 obteniendo el 100\% de similitud. Esta muestra se identificó como Pseudomona cedrina. Para la muestra C3B1 se obtuvieron 1342 nucleótidos, alineando 1306/1321 obteniendo el 99\% de similitud la cual arrojó 2 resultados los cuales fueron Aeromona bestiarium y Aeromona salmonicida, aunque realizando un análisis más profundo en la secuencia nucleotídica se encontró que la cepa era Aeromona salmonicida ya que posee una semejanza nucleotídica en las posiciones 978 y 495. 
Para la muestra C1B1 a partir de la secuencia se obtuvieron 1,342 nucleótidos alineando 1306/1321 obteniendo el 99\% de similitud y arrojando 6 opciones de cepas para esta muestra, las cuales fueron Bacillus lincheniformis, Bacillus amyloliquefaciens, Bacillus methylotrophicus, Bacillus siamensis, Bacillus vallismortis y Bacillus subtilis; por lo que se procedió a analizar la secuencia de nucleótidos, observando que la cepa Bacillus licheniformis poseía menor diferencia nucleotídica en comparación con las demás.

Las múltiples opciones que aparecieron en cada una de las comparaciones son debidas a que las especies del genero Bacillus, están estrechamente relacionados, llegando a ser difícil distinguirlas mediante el análisis de secuencia del gen 16s ribosomal, ya que no hay suficiente divergencia en este gen, dificultando la identificación de estas especies (Wang et al., 2007).

La mayoría de las bacterias rizosféricas como las Pseudomonas spp. y Bacillus spp. tienen alta capacidad de producción de ácido indol-acético, y solubilización de fósforo y potasio, así como atributos de biocontrol como lo es la producción de $\mathrm{HCN}$, sideróforos, enzimas hidrolíticas y antibióticos (Verna 2012).

Existen fuertes evidencias que sugieren que el género Paenibacillus pertenecen al grupo de las bacterias PGPR, entre cuyas características destacan la producción de antiobioticos y formación de biofilms (Timmusj, Grantcharova et al, 2005). La Aeromona salmonicida es una bacteria patógena para los seres humanos, sin embargo es una bacteria destacada en su capacidad de producción de IAA siendo utilizada como bacteria PGPR.

Las bacterias identificadas deben ser estudiadas interactuado con la planta de cebolla, para evaluar su posible uso en la producción biotecnológica de biofertilizantes, que contribuyan a disminuir el uso de fertilizantes químicos en la agricultura.

\section{CONFLICTO DE INTERESES}

Los autores declaran que tienen conflicto de intereses.

\section{REFERENCIAS}

Ahmad F. 2008. Screening of free-living rhizospheric bacteria for their multiple plant growth promoting activities. Microbiological Research. 163(2): 173-181.

Bhowmick P. B. 1986. Production of índole acetic acid by Rhizobium sp. from root nodules of leguminous tree Sesbania grandiflora Pers. Acta Microbial Polon. 35: 181-190.

Datta C. B. 2000. Indole-acetic acid production by a Rhizobium species from root nodules of a leguminous shrub Canajus cojan. Microbiological Research. 155(2): 123-127.

Dullaart J. 1970. The auxin content of root nodules and roots of alnus glutinosa. Journal of Experimental Botany. 21(4): 975-984.

Ehmann A. 1977. The Van Urk-Salkowski reagent-a sensitive and specific chromogenic reagent for silica gel thin-layer chromatographic detection and identification of indole derivates. Journal of Chromatography. 132(2): 267-276. 
Glick B., Penrose D. \& Li J. 1998. A model for the lowering of plant ethylene concentrations by plant growth-promoting bacteria. Journal of Theoretical Biology. 190(1): 63-68.

Hungria M. \& Vargas M. 2000. Enviromental factors simpacting N2 fixation in legumes grown in the tropics with an emphasis on Brazil. Field Crops Research. 65(2): 151-164.

Jimenez-Delgadillo M. 2004. Péptidos secretados por Bacillus subtilis que codifican la arquitectura de la raíz de Arabidopsis thaliana. Phd Dissertation Cinvestav Unidad Irapuato.

Lindow E., Desurmont C., Elkins R., McGourty G., Clark E. \& Brandl M. Ocurrence of Indole3-acetic acid producing bacteria on pear tres and their association with fruit russet. Phytopathology. 88(11): 1149-1157.

Mader P., Fliessbach A., Dubois D., Gunst L., Fried P. \& Niggli U. 2002. Soil fertility and biodiversity in organic farming. Science. 296(5573): 1694-1697.

Mutluru S. \& Konada V. 2007. Bioproduction of índole acetic acid by Rhizobium strains isolated from root nodules of Green manure crop. Iranian Journal of Biotechnology. 5(3): 178-182.

SIAP-SAGARPA 2014. Panorama de Cebolla. Obtenido de Dirección General de Planeación Estratégica, Análisis Sectorial y Tecnologías de la Información. www.finacierarural.gob.mx. (Consultado el 18 de Noviembre de 2016).

Vaghasiat H., Pater G., Chudasama R. \& Bhatt K. 2011. Screening of IAA from rhizospher microflora of field crops. Bioscience Discover. 2(1): 94-100.

Verma J., Yadav J. \& Nath T. 2012. Enhancement of nodulation and yield of chickpea by coinoculation of indigenous Mesorrhizobium spp. and plant growth promoting rhizobacteria in Eastern Uttar Pradesh. Journal Communications in Soil Science and Plant Analysis. 43(2): 605621.

Wahyudi A., Puji r., Widyawati A., Meryandini A. \& Nawangsih A. 2011. Characterization of Bacillus sp. strains isolated from rizosphere of soybean plants for their use as potential plant growth for promoting Rhizobacteria. Journal of Microbiology and Antimicrobials. 3(2): 34-40.

Wang L., Lee F., Tai C. \& Kasai H. 2007. Comparison of gyrB gene sequences, 16s rRNA gene sequences and DNA-DNA hybridiation in the Bacillus subtilis group. International Journal of Systematic and Evolutionary Microbiology. 57(8): 1846-1850.

Woodward A. \& Bartel B. 2005. Auxin: Regulation, action and interaction. Annals of Botany. 95(5): 707-735.

Zarrin F., Saleemi M., Zia M., Sultan T., Aslam M., Rehman RU. \& Chaudhary FM. 2009. Antifungal activity of plant growth-promoting rhizobacteria isolates against Rhizoctonia solani in wheat. African Journal of Biotechnology. 8(2): 219-225.

Zehnder G., Murphy J., Sikora E. \& Kloepper J. 2001. Application to rhizobacteria for induced resistance. European Journal of Plant Pathology. 107(1): 39-50. 